Effects of el astic stress introduced by a silicon nitride cap on sol id-phase crystal I ization of amor phous si I icon

\begin{tabular}{|l|l|}
\hline 著者 & K mur a Yasuo, Ki shi Nasat o, Kat oda Takashi \\
\hline $\begin{array}{l}\text { j ournal or } \\
\text { publ i cat i on t i t l e }\end{array}$ & Jour nal of Appl i ed Physics \\
\hline vol une & 86 \\
\hline number & 4 \\
\hline page r ange & $2278-2280$ \\
\hline year & $1999-08$ 15 \\
\hline URL & ht t p: //hdl . handl e. net /10173/797 \\
\hline
\end{tabular}




\section{AIP Applited Physics}

\section{Effects of elastic stress introduced by a silicon nitride cap on solid-phase crystallization of amorphous silicon}

Yasuo Kimura, Masato Kishi, and Takashi Katoda

Citation: J. Appl. Phys. 86, 2278 (1999); doi: 10.1063/1.371042

View online: http://dx.doi.org/10.1063/1.371042

View Table of Contents: http://jap.aip.org/resource/1/JAPIAU/v86/i4

Published by the American Institute of Physics.

\section{Related Articles}

Chemical vapor deposition of polycrystalline $\mathrm{Fe} 3 \mathrm{O} 4$ thin films by using the cyclohexadiene iron tricarbonyl liquid precursor

J. Appl. Phys. 111, 07B107 (2012)

Columnar grain growth of $\mathrm{FePt}(\mathrm{L} 10)$ thin films

J. Appl. Phys. 111, 07B720 (2012)

$\mathrm{L} 10$ ordered phase formation in $\mathrm{FePt}, \mathrm{FePd}$, CoPt, and CoPd alloy thin films epitaxially grown on $\mathrm{MgO}(001)$ single-crystal substrates

J. Appl. Phys. 111, 07A708 (2012)

Comment on "Forming-free resistive switching behavior in $\mathrm{Nd} 2 \mathrm{O} 3$, Dy2O3, and Er2O3 films fabricated in full room temperature" [Appl. Phys. Lett. 99, 113509 (2011)]

Appl. Phys. Lett. 100, 076101 (2012)

Epitaxial $\mathrm{NiO}$ gate dielectric on $\mathrm{AlGaN} / \mathrm{GaN}$ heterostructures

Appl. Phys. Lett. 100, 063511 (2012)

\section{Additional information on J. Appl. Phys.}

Journal Homepage: http://jap.aip.org/

Journal Information: http://jap.aip.org/about/about_the_journal

Top downloads: http://jap.aip.org/features/most_downloaded

Information for Authors: http://jap.aip.org/authors

\section{ADVERTISEMENT}
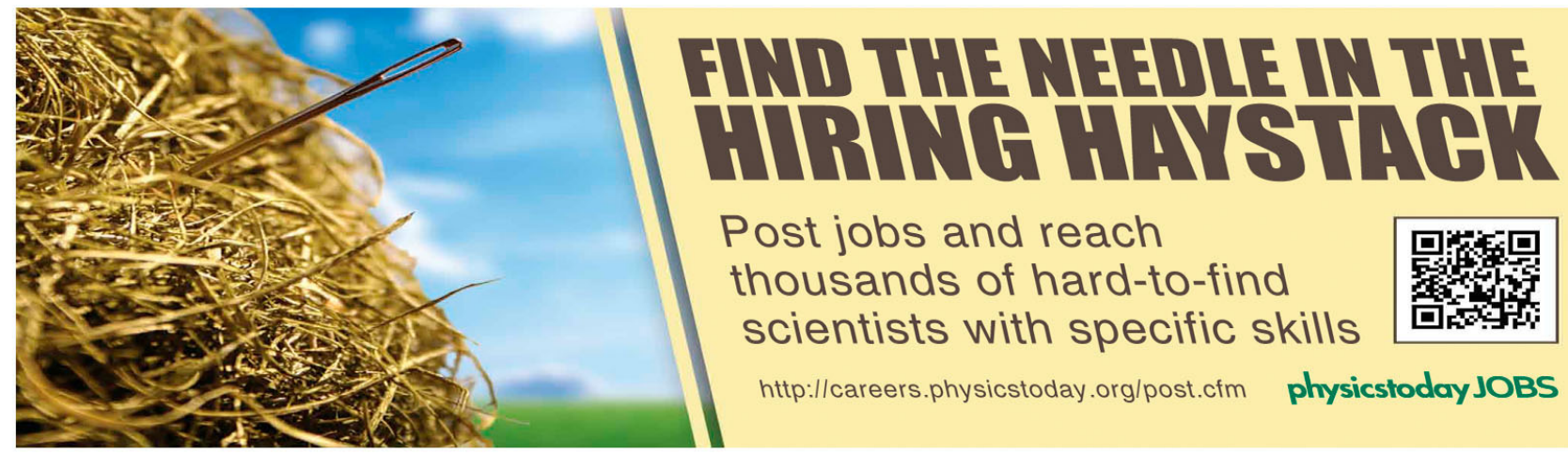


\title{
Effects of elastic stress introduced by a silicon nitride cap on solid-phase crystallization of amorphous silicon
}

\author{
Yasuo Kimuraa) \\ Department of Electronic Engineering, Faculty of Engineering, The University of Tokyo, 7-3-1 Hongo, \\ Bunkyo-ku, Tokyo 113-8656, Japan \\ Masato Kishi and Takashi Katodab) \\ Faculty of Engineering, Kochi University of Technology, Tosayamada, Kochi 782-0003, Japan
}

(Received 14 December 1998; accepted for publication 16 April 1999)

\begin{abstract}
Effects of stress on solid-phase crystallization of amorphous silicon $(a-\mathrm{Si})$ were studied by laser Raman spectroscopy. Compressive stress was introduced in $a$-Si with a $\mathrm{Si}_{3} \mathrm{~N}_{4}$ cap. The speed of crystallization decreased with the increase of the stress while it increased again with an additional cap of $\mathrm{SiO}_{2}$ on a $\mathrm{Si}_{3} \mathrm{~N}_{4}$ cap. $\mathrm{A} \mathrm{SiO}_{2}$ cap introduced tensile stress in an $a$-Si film and relaxed compressive stress by a $\mathrm{Si}_{3} \mathrm{~N}_{4}$ cap. The reason why crystallization of $a$-Si is suppressed is that the stress is elastic and that it does not relax with crystallization. (c) 1999 American Institute of Physics. [S0021-8979(99)07014-0]
\end{abstract}

\section{INTRODUCTION}

Polycrystalline silicon (poly-Si) is an important material in very large-scale integrated circuits (VLSI) and in an application to liquid crystal displays with driving circuits. Solid-phase crystallization of amorphous silicon $(a-\mathrm{Si})$ is one of the methods to form a poly-Si film. It is very important, therefore, to make clear the mechanism of crystallization from $a$-Si to poly-Si in order to control properties of a poly-Si film such as a grain size, electric resistance, and thermal conductivity. However, the mechanism of crystallization of $a$-Si has not been understood clearly yet, especially since the effect of stress on crystallization of an $a$-Si film was not known at all. Very large stress is introduced in a poly-Si film on a glass substrate that is used in liquid crystal displays due to the difference of the thermal expansion coefficient between $\mathrm{Si}$ and glass. It has been reported that crystallization of $a$-Si started at the interface between an $a$-Si film and a substrate and that one of the driving forces of the crystallization is stress due to the difference of a thermal expansion coefficient between $a$-Si and a glass used as a substrate. ${ }^{1}$ On the other hand, there have been reports that nucleation started at the surface of an $a$-Si film when it was kept clean. ${ }^{2,3} \mathrm{We}$ also have reported that crystallization started at the surface of $a$-Si film and that larger stress was accumulated at the interface between $a-\mathrm{Si}$ and a fused silica substrate than at the surface. ${ }^{4}$ Laser Raman spectroscopy is one of the best methods to characterize crystallinity of a material because the phonon frequency measured by it is sensitive to the properties of the material such as the state or structure; that is amorphous or crystalline. In this study, crystallization of an $a$-Si film with stress controlled by the thickness of a silicon nitride $\left(\mathrm{Si}_{3} \mathrm{~N}_{4}\right)$ cap or that of a silicon dioxide $\left(\mathrm{SiO}_{2}\right)$ cap

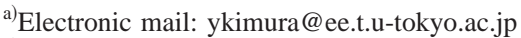

${ }^{b)}$ Electronic mail: katouda@ele.kochi-tech.ac.jp
}

was characterized by laser Raman spectroscopy in order to make clear the effect of stress on crystallization of an $a-\mathrm{Si}$ film.

\section{EXPERIMENT}

Stress cannot be estimated from the extra shift of a Raman frequency from poly-Si because the extra shift depends not only on stress but also on the grain size and the crystalline fraction. Therefore, stress introduced into poly-Si by a dielectric cap is assumed to be one accumulated in a singlecrystal $\mathrm{Si}(100)$ on which a dielectric film is directly deposited by the rf sputtering method. It was characterized by laser Raman spectroscopy based on the extra shift of a Raman frequency.

The sample used for study of crystallization had a structure $\mathrm{SiO}_{2} / \mathrm{Si}_{3} \mathrm{~N}_{4} / a-\mathrm{Si} / \mathrm{Si}_{3} \mathrm{~N}_{4} / \mathrm{Si}(100)$ and $\mathrm{Si}_{3} \mathrm{~N}_{4} / a-\mathrm{Si} /$ $\mathrm{Si}_{3} \mathrm{~N}_{4} / \mathrm{Si}(100)$. Dielectric films, such as $\mathrm{Si}_{3} \mathrm{~N}_{4}$ and $\mathrm{SiO}_{2}$ and an $a$-Si film were deposited by the rf sputtering method at room temperature on a $\mathrm{Si}(100)$ substrate. The thickness of a $\mathrm{Si}_{3} \mathrm{~N}_{4}$ film on $\mathrm{Si}(100)$ and that of an $a$-Si film were $50 \mathrm{~nm}$ and $1.5 \mu \mathrm{m}$, respectively. For the samples without a $\mathrm{SiO}_{2}$ cap, the thickness of a $\mathrm{Si}_{3} \mathrm{~N}_{4}$ cap was varied from 50 to 1000 $\mathrm{nm}$ and for those with a $\mathrm{SiO}_{2}$ cap, the thickness of a $\mathrm{Si}_{3} \mathrm{~N}_{4}$ cap was fixed at $750 \mathrm{~nm}$ and that of a $\mathrm{SiO}_{2}$ cap was varied from 200 to $600 \mathrm{~nm}$. All samples were annealed at $500{ }^{\circ} \mathrm{C}$ for $6 \mathrm{~h}$ in $\mathrm{Ar}+\mathrm{H}_{2}(6 \%)$ in order to stabilize films and were annealed at $750{ }^{\circ} \mathrm{C}$ in the same atmosphere in order to transform $a$-Si into poly-Si. Dielectric caps on an $a$-Si film were removed after all annealing.

The crystallinity was characterized also by laser Raman spectroscopy. Raman spectra were obtained using a triplemonochrometer JEOL JRS-400T. The wavelength of the probe light was $514.5 \mathrm{~nm}$. A $\mathrm{Si}_{3} \mathrm{~N}_{4}$ cap and a $\mathrm{SiO}_{2}$ cap were removed before the measurement of laser Raman spectroscopy because a Raman peak of $a-\mathrm{Si}$ is so weak and broad that it cannot be measured without removing a $\mathrm{Si}_{3} \mathrm{~N}_{4}$ cap which absorbs the probe light. 


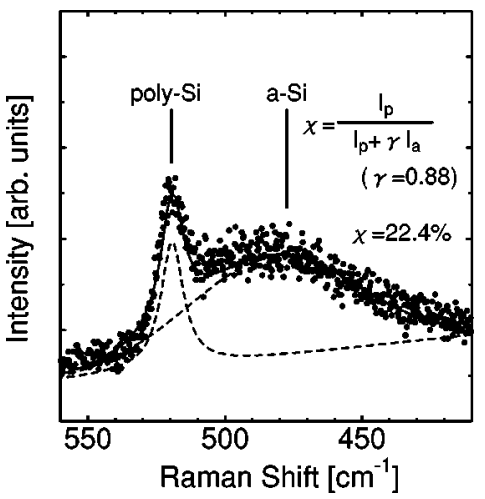

FIG. 1. Definition of the crystalline fraction $\chi$. A typical Raman spectrum of $p$-Si consists of two peaks: one due to the crystal and the other due to $a$-Si. A crystalline fraction $\chi$ is defined by $I_{p} /\left(I_{p}+\gamma I_{a}\right)$, where $I_{p}$ and $I_{a}$ are the area of the peak due to crystal and $a-\mathrm{Si}$, respectively, and $\gamma$ is the ratio of the scattering cross section.

As shown in Fig. 1, the crystalline fraction $\chi$ of poly-Si was obtained from a Raman spectrum using the expression,

$$
\chi=\frac{I_{p}}{I_{p}+\gamma I_{a}}
$$

where $I_{p}$ and $I_{a}$ are the areas of the peaks of poly-Si and $a-\mathrm{Si}$, respectively, and $\gamma$ is the ratio of the scattering cross section. $\gamma$ is a very important factor to estimate the crystalline fraction from a Raman spectrum but it varies with grain size. It has been reported that the value of $\gamma$ is 0.88 when a grain size is small or when crystalline fraction is small. ${ }^{5}$ In this study the early stage of crystallization is discussed. Therefore, 0.88 was used as the value of $\gamma . I_{p}$ and $I_{a}$ were obtained by means of the least squares method assuming that the shape of a poly-Si peak was Lorenzian and that of an $a$-Si peak was Gaussian.

\section{RESULTS AND DISCUSSION}

Figure 2 shows Raman shift for a $\mathrm{Si}(100)$ substrate in which stress was accumulated by a $\mathrm{Si}_{3} \mathrm{~N}_{4}$ film or a $\mathrm{SiO}_{2}$ film at a room temperature. Raman shift of the reference which was a stress-free $\mathrm{Si}(100)$ substrate without dielectric films

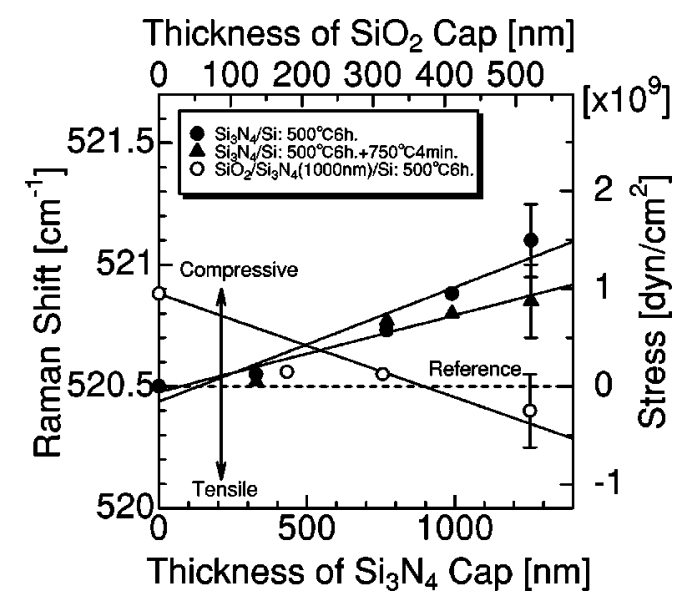

FIG. 2. Raman shift of a $\mathrm{Si}(100)$ substrate stressed by a $\mathrm{Si}_{3} \mathrm{~N}_{4}$ film or a $\mathrm{SiO}_{2}$ film.

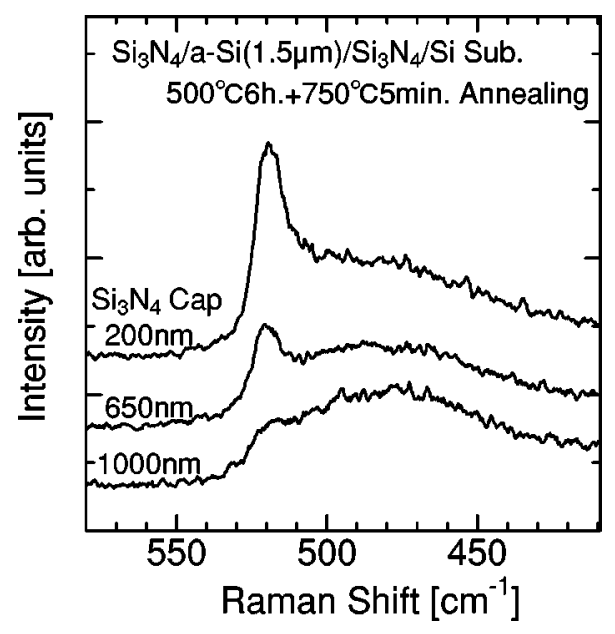

FIG. 3. Dependence of the Raman spectrum from a poly-Si film with a $\mathrm{Si}_{3} \mathrm{~N}_{4}$ cap on the thickness of a $\mathrm{Si}_{3} \mathrm{~N}_{4}$ cap.

was $520.5 \mathrm{~cm}^{-1}$. Raman shift for a $\operatorname{Si}(100)$ substrate with a $\mathrm{Si}_{3} \mathrm{~N}_{4}$ cap was larger than that for the reference and increased with the thickness of a $\mathrm{Si}_{3} \mathrm{~N}_{4}$ cap. $\mathrm{A} \mathrm{Si}_{3} \mathrm{~N}_{4}$ cap annealed at $500^{\circ} \mathrm{C}$ introduced compressive stress into the $\mathrm{Si}(100)$ substrate at room temperature and the quantity of the stress was independent of annealing at $750{ }^{\circ} \mathrm{C}$ following annealing at $500^{\circ} \mathrm{C}$. When the thickness of a $\mathrm{Si}_{3} \mathrm{~N}_{4}$ cap was 1 $\mu \mathrm{m}$, stress in a $\mathrm{Si}(100)$ substrate estimated from an extra peak shift was $1.17 \times 10^{9} \mathrm{dyn} / \mathrm{cm}^{2}$, which was 2 orders larger than that estimated by the bimetal model assuming that the stress was caused by a difference of the thermal expansion coefficients between a $\mathrm{Si}_{3} \mathrm{~N}_{4}$ cap and a $\mathrm{Si}$ substrate. The compressive stress by a $\mathrm{Si}_{3} \mathrm{~N}_{4}$ cap was independent of temperature because it was not due to the difference of the thermal expansion coefficient, but was due to the intrinsic stress in a $\mathrm{Si}_{3} \mathrm{~N}_{4}$ cap. ${ }^{6}$

Raman shift for a $\mathrm{Si}(100)$ substrate with a $\mathrm{SiO}_{2} /$ $\mathrm{Si}_{3} \mathrm{~N}_{4}(750 \mathrm{~nm})$ cap decreased with the thickness of a $\mathrm{SiO}_{2}$ cap. A $\mathrm{SiO}_{2}$ cap relaxed stress introduced by a $\mathrm{Si}_{3} \mathrm{~N}_{4}$ cap because the nature of stress by a $\mathrm{SiO}_{2}$ cap is opposite to that by a $\mathrm{Si}_{3} \mathrm{~N}_{4}$ cap, that is, stress by a $\mathrm{SiO}_{2}$ cap is tensile and that by a $\mathrm{Si}_{3} \mathrm{~N}_{4}$ cap is compressive.

Figure 3 shows the Raman spectra from $a$-Si films with only a $\mathrm{Si}_{3} \mathrm{~N}_{4}$ cap. The samples were annealed at $750^{\circ} \mathrm{C}$ for 5 min after annealing at $500{ }^{\circ} \mathrm{C}$ for $6 \mathrm{~h}$. The spectrum consists of two peak. One was around $520 \mathrm{~cm}^{-1}$ corresponding to crystalline $\mathrm{Si}(c-\mathrm{Si})$. The other was a broad peak around 480 $\mathrm{cm}^{-1}$ corresponding to $a$-Si. Obviously, the intensity of the Raman peak from $c$-Si decreased with the thickness of a $\mathrm{Si}_{3} \mathrm{~N}_{4}$ cap. Figure 4 shows the crystalline fraction versus annealing time which was obtained from Raman spectra. An $a$-Si film with a thin $\mathrm{Si}_{3} \mathrm{~N}_{4}$ cap crystallized faster than that with a thick $\mathrm{Si}_{3} \mathrm{~N}_{4}$ cap. A value of crystalline fraction saturated finally to almost the same one for all samples and the value did not depend on the thickness of the $\mathrm{Si}_{3} \mathrm{~N}_{4}$ cap, although the absolute value contained some errors because the value of scattering cross section depends on the grain size of poly-Si. 


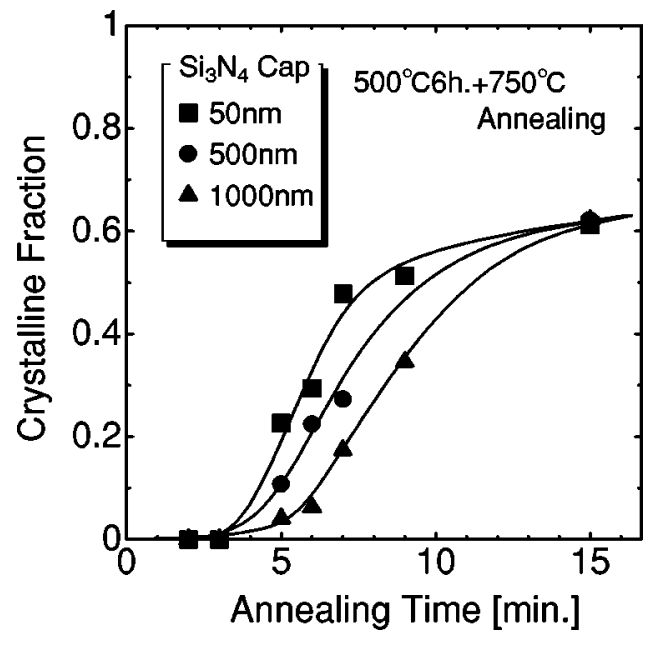

FIG. 4. The crystalline fraction of poly-Si vs annealing time.

Figure 5 shows Raman spectra from the samples with a $\mathrm{SiO}_{2}$ cap which was deposited on $\mathrm{Si}_{3} \mathrm{~N}_{4}$ cap of $750 \mathrm{~nm}$. An intensity of Raman peak from poly-Si increased with the thickness of a $\mathrm{SiO}_{2}$ cap and the speed of crystallization suppressed by a $\mathrm{Si}_{3} \mathrm{~N}_{4}$ film was recovered again. When it was assumed that the suppression of the crystallization by a $\mathrm{Si}_{3} \mathrm{~N}_{4}$ cap would be due to sputtering, the effect of a $\mathrm{SiO}_{2}$ cap must be the same as that of a $\mathrm{Si}_{3} \mathrm{~N}_{4}$ cap. However, the effect of a $\mathrm{SiO}_{2}$ cap on a $\mathrm{Si}_{3} \mathrm{~N}_{4}$ cap was opposite to that of a

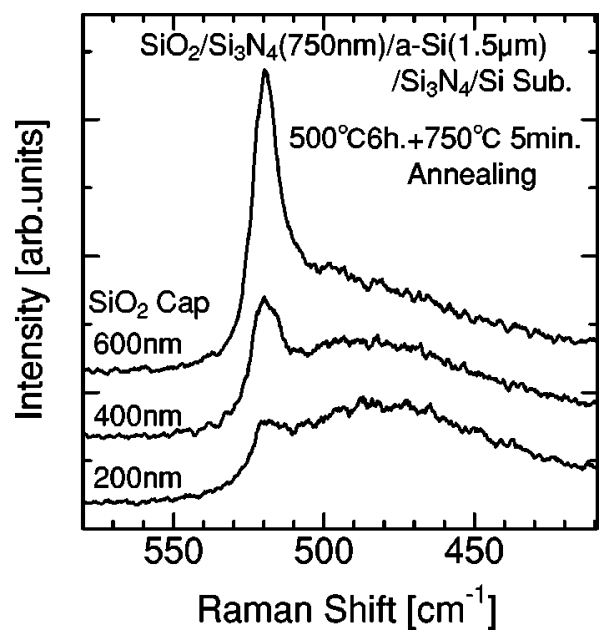

FIG. 5. Dependence of the Raman spectrum from a poly-Si film with a $\mathrm{SiO}_{2} / \mathrm{Si}_{3} \mathrm{~N}_{4}(750 \mathrm{~nm})$ cap on the thickness of a $\mathrm{SiO}_{2}$ cap.
$\mathrm{Si}_{3} \mathrm{~N}_{4}$ cap. Therefore, the suppression of crystallization by a $\mathrm{Si}_{3} \mathrm{~N}_{4}$ cap was due to compressive stress introduced into an $a$-Si film.

We need to distinguish between elastic and plastic strain in discussing effects of strain on crystallization. Strain in this work is elastic while strain which has been considered to promote crystallization is plastic. We propose in this paper that elastic strain, which is introduced in this work, does not relax with phase transformation while plastic strain relaxes with phase transformation and promotes crystallization. Elastic modulus of $c$-Si is larger than that of $a-\mathrm{Si}^{7}{ }^{7,8}$ Therefore, elastic strain which does not relax causes an increase of strain energy with phase transformation, assuming that strain shows no change with phase transformation when crystalline fraction is small. Consequently the difference of free energy between $a$-Si and $c$-Si decreases with strain in an $a$-Si film. As a result, crystallization was suppressed.

\section{CONCLUSION}

Effects of stress on solid-phase crystallization in an $a-\mathrm{Si}$ film was studied by laser Raman spectroscopy. We found that compressive stress suppresses the speed of crystallization which can be controlled by a simple method in which compressive stress is adjusted by controlling a thickness of a $\mathrm{Si}_{3} \mathrm{~N}_{4}$ cap or $\mathrm{SiO}_{2}$ cap on an $a$-Si film. A $\mathrm{Si}_{3} \mathrm{~N}_{4}$ cap introduced compressive stress and a $\mathrm{SiO}_{2}$ cap introduced tensile stress That is, a $\mathrm{Si}_{3} \mathrm{~N}_{4}$ cap on an $a$-Si film suppresses crystallization while another $\mathrm{SiO}_{2}$ cap on a $\mathrm{Si}_{3} \mathrm{~N}_{4}$ cap recovers the speed of crystallization suppressed by a $\mathrm{Si}_{3} \mathrm{~N}_{4}$ cap. The reason why stress suppresses crystallization of an $a$-Si film is that introduced strain is elastic and that it does not relax with crystallization. Elastic strain that does not relax causes an increase in strain energy with phase transformation because elastic modulus of $c$-Si is larger than that of $a-\mathrm{Si}^{7,8}$ and the difference of free energy between $a-\mathrm{Si}$ and $c$-Si decreases. As a result, elastic stress suppresses crystallization.

${ }^{1}$ M. Momiwa, M. Miyao, R. Tsuchiyama, M. Ichikawa, H. Sunami, and T. Tokuyama, Appl. Phys. Lett. 47, 113 (1985).

${ }^{2}$ H. Watanabe, N. Aoto, S. Adachi, and T. Kikkawa, J. Appl. Phys. 71, 3538 (1992).

${ }^{3}$ A. Sakai, T. Tatsumi, and T. Niino, Jpn. J. Appl. Phys., Part 2 30, L941 (1991).

${ }^{4}$ Y. Kimura and T. Katoda, Appl. Surf. Sci. 117, 790 (1997).

${ }^{5}$ R. Tsu, J. Gonzalez-Hernandez, S. S. Chao, S. C. Lee, and K. Tanaka, Appl. Phys. Lett. 40, 534 (1982).

${ }^{6}$ M. Maeda and K. Ikeda, J. Appl. Phys. 83, 3865 (1998).

${ }^{7}$ W. A. Brantley, J. Appl. Phys. 44, 534 (1973).

${ }^{8}$ Y. Tatsumi, M. Shigi, and M. Hirata, Jpn. J. Appl. Phys. 17, 1465 (1978). 